\title{
Luminal ions and short chain fatty acids as markers of functional activity of the mucosa in ulcerative colitis
}

\author{
WEW ROEDIGER,* M HEYWORTH, $\dagger$ P WILlOUGHBY, $\dagger$ J PIRIS, $\ddagger$ A MOORE, \\ SC TRUELOVE $\dagger$
}

From the Nuffield Departments of *Surgery, $\uparrow$ Clinical Medicine, $\ddagger$ Pathology and §Clinical Biochemistry, Radcliffe Infirmary, Oxford

SUMMARY Luminal concentrations of short chain fatty acids (SCFA), ammonia, sodium and potassium were measured in colonic dialysate of 16 control subjects and in 65 cases with ulcerative colitis (UC), which were graded according to mucosal changes into mild (1), moderate (2), or severe (3) inflammatory activity. Sodium concentrations were mildly but not significantly increased in severe ulcerative colitis while luminal potassium concentrations were markedly decreased in severe ulcerative colitis $(p<0.025)$. Concentrations of SCFA were increased in severe ulcerative colitis. Butyrate concentrations were significantly raised in all stages of active ulcerative colitis even when other fatty acids were not raised. Of all the parameters a lowered $\mathrm{pH}$ and raised butyrate concentration most strikingly correlate with the severity of mucosal change. Results indirectly suggest that control of luminal $\mathrm{pH}$, potassium secretion and utilisation of butyrate by the colonic mucosa are impaired with progressive mucosal inflammation.

The colonic epithelium governs absorption of ions and bacterial short chain fatty acids (SCFA) which constitute the greatest proportion of anions in stool water. ${ }^{1}$ Short chain fatty acids provide up to $70 \%$ of respiratory energy for epithelial cells of the mucosa ${ }^{2}$ and furthermore augment sodium absorption in the healthy colon. ${ }^{3} 4$

In ulcerative colitis (UC) the mucosa is unable to utilise SCFA as respiratory fuel suggesting that an energy deficiency state exists in the disease. ${ }^{5}$ Indirect support for an energy deficient state is a defect in active (energy-requiring) absorption of sodium recently found in the mucosa of UC. ${ }^{6}$

In the light of the above findings a study was undertaken to clarify the relation between luminal SCFA, luminal sodium and inflammatory activity of the mucosa in UC. The method chosen was in vivo colonic dialysis which reflects the ability of the colonic mucosa to absorb ions and SCFA. ${ }^{7}$ Dialysis particularly is an index of equilibration across the distal colonic mucosa which is readily assessed by histological means.

\section{Material and methods}

Gelatin capsules containing dialysis tubing were Accepted for publication 3 August 1981 prepared, administered and collected as described by Wrong et al ${ }^{1}$ with the exception that the tubing was filled with Dextran containing $5 \%$ dextrose (Fisons Ltd).

All subjects (Table 1) were ambulant and living at home when taking the dialysis capsules. A sigmoidoscopic examination with rectal biopsy was performed on every patient with UC on the day on which the capsules were taken. Grading was performed as described by Truelove and Richards ${ }^{9}$ and was as follows:

$\mathbf{0}=$ normal appearance of mucosa and no inflammation in biopsy

$1=$ mild

$2=$ moderate

3 = severe activity in the mucosa or inflammatory change on biopsy.

Table 1 Ages (mean $\pm S E M$ ) and sex distribution of subjects in control group and patients with ulcerative colitis

\begin{tabular}{llll} 
Control & \multicolumn{3}{l}{ Ulcerative colitis } \\
\cline { 2 - 4 } & $\begin{array}{l}\text { In } \\
\text { remission }\end{array}$ & \multicolumn{2}{l}{ Activity score } \\
\cline { 3 - 4 } & & 1 & 2
\end{tabular}

\begin{tabular}{|c|c|c|c|c|c|}
\hline Age (yr) & $41 \cdot 2 \pm 3.9$ & $42 \cdot 8 \pm 2.6$ & $37.1 \pm 2.6$ & $42 \cdot 4 \pm 3.4$ & $47.4 \pm 3.7$ \\
\hline & $\begin{array}{l}16 \\
6: 10\end{array}$ & & & $\begin{array}{l}15 \\
14: 2\end{array}$ & \\
\hline
\end{tabular}


With one or two exceptions all the patients with UC were receiving Salazopyrin and every one in group 3 was receiving prednisolone by mouth and in the form of a rectal enema or by both routes. In order to obtain accurate results patients were requested to stop using these enemas while taking and collecting the capsules.

Control subjects attended the irritable bowel clinic. Criterion for regarding them as suitable was the presence of a normal colonic mucosa as judged by sigmoidoscopy, rectal biopsy or barium enema all of which had been performed within three months before the dialysis capsules were taken.

\section{METHODS}

The $\mathrm{pH}$ was measured with a Radiometer micro $\mathrm{pH}$ electrode. Sodium and potassium were estimated by flame photometry and ammonia with glutamate dehydrogenase ${ }^{10}$ after $1 / 10$ dilution of samples to avoid interference by bile pigments with spectrophotometric measurements. Short chain fatty acids were measured as described by Roediger and
Moore. ${ }^{4}$ Rectal biopsies were fixed in formalin-saline or formalin-sublimate. Sections stained with haematoxylin and eosin were assessed and graded according to Truelove and Richards ${ }^{9}$ for inflammatory activity.

There was insufficient dialysate in several cases for measuring all the ions indicated above. Samples were then randomly allocated for measurement of one or other parameter.

\section{Results}

The content of $\mathrm{Na}, \mathrm{K}, \mathrm{NH}_{3}$ (Table 2) and SCFA (Table 3 ) in the dialysate from the control group were similar to those reported by Wrong et al ${ }^{1}$ and Rubinstein et al. ${ }^{11}$ Both of these studies were conducted in healthy volunteers in whom the colonic mucosa was not biopsied.

The luminal sodium content was raised in patients with severe inflammation but this change was not statistically significant. Potassium concentrations were lower in the group with moderate and severe colitis than in patients in complete remission but the

Table 2 Cationic content of faecal dialysate. Estimations (mmol/l) are mean $\pm S E M$ of the number of patients in each column

\begin{tabular}{|c|c|c|c|c|c|}
\hline & \multirow[t]{3}{*}{ Control } & \multicolumn{4}{|c|}{ Ulcerative colitis } \\
\hline & & \multirow[t]{2}{*}{ In remission } & \multicolumn{3}{|l|}{ Activity score } \\
\hline & & & 1 & 2 & 3 \\
\hline $\begin{array}{l}\text { No of patients } \\
\mathrm{Na}\end{array}$ & $\begin{array}{l}16 \\
21 \cdot 63 \pm 4 \cdot 99 \\
\text { NS }\end{array}$ & $\begin{array}{l}25 \\
18 \cdot 00 \pm 3 \cdot 73 \\
\mathrm{NS}\end{array}$ & $\begin{array}{l}15 \\
15 \cdot 60 \pm 3 \cdot 76 \\
\text { NS }\end{array}$ & $\begin{array}{l}15 \\
24 \cdot 38 \\
\text { NS }\end{array}$ & $\begin{array}{l}9 \\
32 \cdot 11 \\
\text { NS }\end{array}$ \\
\hline $\mathbf{K}$ & $79 \cdot 56 \pm 5 \cdot 92$ & $\begin{array}{l}87 \cdot 15 \pm 4 \cdot 71 \\
\text { NS }\end{array}$ & $\begin{array}{l}71 \cdot 23 \pm 6 \cdot 18 \\
\mathrm{NS}\end{array}$ & $\begin{array}{l}65 \cdot 64 \pm 7.08 \\
\text { NS }\end{array}$ & $\begin{array}{l}59.55 \pm 7.21 \\
p<0.025\end{array}$ \\
\hline $\mathrm{Na}: \mathrm{K}$ & $0.40 \pm 0.17$ & $\begin{array}{l}0.35 \\
\text { NS }\end{array}$ & $\begin{array}{l}0.28 \pm 0.09 \\
\text { NS }\end{array}$ & $\begin{array}{l}0.73 \pm 0.35 \\
\text { NS }\end{array}$ & $\begin{array}{l}0.70 \pm 0.17 \\
\mathrm{NS}\end{array}$ \\
\hline $\begin{array}{l}\text { Ammonia } \\
\text { (No of patients) }\end{array}$ & $\begin{array}{l}9 \cdot 91 \\
(15)\end{array} \pm 1 \cdot 43$ & $\begin{array}{l}11 \cdot 18 \pm 1 \cdot 39 \\
(26) \\
\text { NS }\end{array}$ & $\begin{array}{l}16.48 \pm 2.54 \\
(15) \\
p<0.025\end{array}$ & $\begin{array}{l}11 \cdot 51 \pm 1 \cdot 70 \\
(15) \\
\text { NS }\end{array}$ & $\begin{array}{l}22.08 \pm 2.64 \\
(9) \\
p<0.001\end{array}$ \\
\hline
\end{tabular}

Student's $t$ test : control $v$ ulcerative colitis.

Table $3 p H$ and fatty acid content of faecal dialysate. Estimations (mmol/l) are mean $\pm S E M$ of the number of patients in parentheses

\begin{tabular}{|c|c|c|c|c|c|}
\hline & \multirow[t]{3}{*}{ Control } & \multicolumn{4}{|c|}{ Ulcerative colitis } \\
\hline & & \multirow[t]{2}{*}{ In remission } & \multicolumn{3}{|l|}{ Activity score } \\
\hline & & & 1 & 2 & 3 \\
\hline pH & $\begin{array}{l}7.47 \\
(16)\end{array} \pm 0.19$ & $\begin{array}{l}7 \cdot 59 \pm 0 \cdot 12 \\
(24) \\
\text { NS }\end{array}$ & $\begin{array}{l}6.92 \pm 0.28 \\
(14) \\
\text { NS }(p<0.06)\end{array}$ & $\begin{array}{l}6.86 \pm 0.16 \\
(15) \\
p<0.025\end{array}$ & $\begin{array}{l}6.21 \pm 0.13 \\
(9) \\
\mathrm{p}<0.001\end{array}$ \\
\hline Acetate & $\begin{array}{l}53.52 \pm 5.75 \\
(14)\end{array}$ & $\begin{array}{l}48 \cdot 96 \pm 4.27 \\
(25) \\
\text { NS }\end{array}$ & $\begin{array}{l}53.77 \pm 7.03 \\
(16) \\
\text { NS }\end{array}$ & $\begin{array}{l}50.23 \pm 4.05 \\
(14) \\
\text { NS }\end{array}$ & $\begin{array}{l}79.87 \pm 3.74 \\
(9) \\
p<0.001\end{array}$ \\
\hline Propionate & $\begin{array}{l}22 \cdot 72 \pm 2 \cdot 44 \\
(14)\end{array}$ & $\begin{array}{l}24 \cdot 52 \pm 2 \cdot 39 \\
(25) \\
\text { NS }\end{array}$ & $\begin{array}{l}28 \cdot 20 \pm 4.48 \\
(1.6) \\
\text { NS }\end{array}$ & $\begin{array}{l}27 \cdot 23 \pm 2 \cdot 27 \\
(14) \\
\text { NS }\end{array}$ & $\begin{array}{l}40.87 \pm 4.99 \\
(9) \\
p<0.0025\end{array}$ \\
\hline$n$-butyrate & $\begin{array}{l}14 \cdot 02 \pm 1.6 \\
(14)\end{array}$ & $\begin{array}{l}16 \cdot 20 \pm 1 \cdot 18 \\
(25) \\
\text { NS }\end{array}$ & $\begin{array}{l}18.81 \pm 1.85 \\
(16) \\
p<0.05\end{array}$ & $\begin{array}{l}18.85 \pm 2.15 \\
(14) \\
p<0.05\end{array}$ & $\begin{array}{l}35.02 \pm 3.61 \\
(9) \\
p<0.001\end{array}$ \\
\hline
\end{tabular}

Student's $t$ test : control $v$ ulcerative colitis. 
change was only significantly different $(p<0.025)$ in the group with severe colitis.

The $\mathrm{pH}$ values of stool are given in Table 3. In active UC the $\mathrm{pH}$ was lower than in control subjects although in mild colitis the difference was not quite significant $(\mathrm{p}<0.06)$.

The concentration of all three fatty acids, acetate, propionate and butyrate were significantly increased in severe colitis. In the other groups of active colitis only $n$-butyrate was consistently and significantly raised, and the concentration seemed to correlate with the severity of the disease.

\section{Discussion}

The concentration of the various ions in stool water are the outcome of electrolyte movement across the mucosa and thus an indication of electrolyte absorption or secretion. ${ }^{78}$ Whether dialysate is a good reflector of mucosal function in diarrhoea is not clear as hastened transit might decrease the efficiency of electrolyte movement across the mucosa but not necessarily across the dialysis membrane. Equilibration across the membrane is usually achieved within 60 min. ${ }^{1} \mathrm{~A}$ further restriction of colonic dialysis is that it does not reflect the quantity of ion excreted with respect to time but merely reflects equilibration of ions across the mucosa under the conditions of study.

Subject to the above limitation dialysate did indicate a change in electrolyte handling by the mucosa in UC. The altered $\mathrm{Na}: \mathrm{K}$ ratio in mild or moderate inflammation was not significant and in line with findings of Rask-Madsen ${ }^{12} 13$ who found no change in sodium absorption in mild UC. During acute attacks sodium absorption is usually reduced. 121415 We only detected a trend in this direction which was not significantly different from control subjects possibly due to the action of corticosteroids. These augment sodium absorption in the colon and prevent the defective sodium transport now known to occur in the mucosa of severe UC. ${ }^{6}$

The low luminal content of potassium presently observed suggests that potassium secretion was impaired. Some studies with colonic irrigation in vivo indicate that potassium secretion is enhanced in severe colitis. ${ }^{1415}$ Other studies indicate the opposite. Rask-Madsen found no enhanced secretion of potassium in severe colitis and clinically Smiddy et al ${ }^{16}$ could not confirm a notable loss of potassium in patients with severe disease. Failure of potassium secretion (usually an active metabolic process ${ }^{17}$ ) provides some support for an energy deficiency state $^{5}$ in ulcerative colitis in that the colonic mucosa is unable to transport potassium into the colonic lumen at the normal rate.
In general the $\mathrm{pH}$ of the colonic contents depends upon the concentration of ammonia, ${ }^{18}$ the concentration of SCFA ${ }^{19}$ and the concentration of bicarbonate. ${ }^{20}$ Low concentrations of bicarbonate and high concentrations of ammonia and fatty acids are associated with a low $\mathrm{pH}$. In the present study the luminal $\mathrm{pH}$ was low in patients with active UC of moderate severity despite ammonia and fatty acid concentration that were within the range of the control group. It is adduced that the low $\mathrm{pH}$ in this group of patients is due to failure of bicarbonate secretion into the colonic lumen. A low pH of stool water in UC was also found by Shoskes in $1947^{21}$ but it remains conjectural whether the low $\mathrm{pH}$ is the actual cause of the diarrhoea which is a usual feature of this disease. Certainly absorption of ions in the normal mammalian colon can occur as efficiently at a $\mathrm{pH}$ of 5.0 as at a $\mathrm{pH}$ of 7.0.17 18

Of the three SCFA measured, $n$-butyrate consistently showed raised concentrations in UC. All three fatty acids are absorbed by the normal colon but the rate of absorption for each individual acid is not known. The possibility exists that the rate of absorption of SCFA in the colon is determined by the extent to which each is metabolised in the mucosa. Thus $n$-butyrate is predominantly oxidised in the colonic mucosa of mammals ${ }^{22}$ including man $^{2}$ while in UC there is an inability to utilise $n$-butyrate. ${ }^{5}$ Persistently raised concentrations of $n$-butyrate in all severities of mucosal inflammation could reflect this impaired metabolism.

Of all the factors a lowered $\mathrm{pH}$ and raised butyrate concentration most strikingly correlate with the severity of mucosal change. In addition dialysate provided evidence of impaired potassium secretion and also of impaired sodium absorption. All these features can readily be associated with an energy deficiency state of the diseased mucosa which inefficiently regulates active movement of ions through the surface epithelial cells of the colon.

\section{References}

1 Wrong O, Metcalfe-Gibson A, Morrison RBI, $\mathrm{Ng} \mathrm{ST}$, Howard AV. In vivo dialysis of faeces as a method of stool analysis. Clin Sci 1965;28:357-75.

2 Roediger WEW. The role of anaerobic bacteria in the metabolic welfare of the colonic mucosa in man. Gut 1980;21 :793-8.

${ }^{3}$ Ruppin H, Bar-Meir S, Soergel KH, Wood CM, Schmitt MG Jr. Absorption of short-chain fatty acids by the colon. Gastroenterology 1980;78:1500-7.

${ }^{4}$ Roediger WEW, Moore A. The effect of short-chain fatty acid on sodium absorption in the isolated human colon perfused through the vascular bed. Digest Dis 1981 ;26: 100-6.

5 Roediger WEW. The colonic epithelium in ulcerative colitis: an energy-deficiency disease? Lancet 1980;ii: 712-5. 
${ }^{6}$ Hawker PC, McKay JS, Turnberg LA. Electrolyte transport across colonic mucosa from patients with inflammatory bowel disease. Gastroenterology 1980;79:508-11.

${ }^{7}$ Edmonds CJ. Absorption of sodium and water by human rectum measured by a dialysis method. Gut 1971;12: 356-62.

${ }^{8}$ McNeil NI, Cummings JH, James WPT. Short-chain fatty acid absorption by the human large intestine. Gut 1978; 19:819-22.

${ }^{9}$ Truelove SC, Richards WCD. Biopsy studies in ulcerative colitis. Br Med J 1956;i:1315-8.

${ }^{10}$ Bergmeyer HU. Methods of enzymatic analysis. Vol 3. New York: Academic Press, 1974.

${ }^{1}$ Rubinstein R, Howard AV, Wrong OM. In vivo dialysis of faeces as a method of stool analysis IV. The organic anion component. Clin Sci 1979;37:549-64.

12 Rask-Madsen J. The relationship between sodium fluxes and electrical potentials across the normal and inflamed human rectal wall in vivo. Acta Med Scand 1973;194: 311-7.

${ }^{13}$ Rask-Madsen J. Functional alterations in ulcerative colitis. In: Robinson JWL, ed. Intestinal ion transport. Lancaster: MTP, 1976:381-97.

1 ' Duthie HL, Watts JM DeDombal FT, Goligher JC. Serum electrolytes and colonic transfer of water and electrolytes in chronic ulcerative colitis. Gastroenterology. 1964;47:525-30.

${ }^{15}$ Harris J, Shields R. Absorption and secretion of water and electrolytes by the intact human colon in diffuse untreated proctocolitis. Gut 1970;11:27-33.

${ }^{16}$ Smiddy FG, Gregory SD, Smith IB, Goligher JC. Faecal loss of fluid, electrolytes and nitrogen in colitis before and after ileostomy. Lancet 1960;i:14-9.

${ }^{17}$ Hawker PC, Mashiter KE, Turnberg LA. Mechanisms of transport of $\mathrm{Na}, \mathrm{Cl}$ and $\mathrm{K}$ in the human colon. Gastroenterology 1978;74:1241-7.

${ }^{18}$ Bown RL, Gibson JA, Fenlon JCB, Snedden W, Clark ML, Sladen GE. Ammonia and urea transport by the excluded human colon. Clin Sci Mol Med 1975;48:279-87.

${ }^{19}$ Wrong OM. The role of the human colon in homeostasis. In: Gilliland I, Francis J, eds. The scientific basis of medicine (annual reviews). Vol 11. University of London: Athlone Press for the British Postgraduate Medical Federation, 1971:192-215.

${ }^{20}$ Down PF, Agostini L, Murison J, Wrong OM. The interrelations of faecal ammonia, $\mathrm{pH}$ and bicarbonate: evidence of colonic absorption of ammonia by non-ionic diffusion. Clin Sci 1972;43:101-14.

${ }^{21}$ Shoshkes M. The hydrogen ion concentration of the faeces. Gastroenterology 1947;9:765-72.

${ }^{22}$ Rousseau B, Sladen GE. Effect of luminal $\mathrm{pH}$ on the absorption of water, sodium and chloride by rat intestine in vivo. Biochim Biophys Acta 1971;233:591-3.

${ }^{23}$ Henning SJ, Hird FJ. Ketogenesis from butyrate and acetate by the caecum and the colon of rabbits. Biochem $J$ 1972;130:785-90.

Requests for reprints to: Dr WEW Roediger, Department of Surgery, Prince Henry's Hospital, St Kilda Road, Melbourne, Victoria 3004, Australia. 